\title{
AUTONOMIA DAS CRIANÇAS VERSUS CONTROLE INSTITUCIONAL: UMA ANÁLISE DA AGÊNCIA INFANTIL \\ EM UMA CASA ABRIGO DE IMPERATRIZ
}

\section{CHILDREN'S AUTONOMY VERSUS INSTTTUTIONAL CON- TROL: AN ANALYSIS OF CHILDREN'S AGENCY AT A SHELTER HOME IN IMPERATRIZ CITY}

\author{
Jéssica de Sousa Lima* \\ Emilene Leite de Sousa**
}

Introdução

Este artigo consta de uma análise ${ }^{1}$ da agência das crianças que vivem na Casa da Criança da cidade de Imperatriz - Maranhão, a partir da distinção de conceitos como universo infantil e autonomia infantil trabalhados por Sousa (2018). Embora o campo da Antropologia da criança tenha crescido no Brasil, ainda são muitos os estudos que se dedicam à análise da infância através de pesquisa sobre crianças e não necessariamente com crianças.

Isso resulta no fato de que há muitas pesquisas sendo feitas sobre a infância e as crianças, que tomam o ponto de vista dos pais, professores e cuidadores em detrimento do ponto de vista das próprias crianças. Quando isso ocorre, sob diversos aspectos, a agência infantil não é considerada. Parecemos estar olhando para as crianças nelas mesmas, mas estamos enxergando-as, em suas palavras e ações, a partir do ponto de vista dos adultos.

Essa negligência em relação às crianças e o não reconhecimento da importância de suas ações na construção dos sistemas sociais resultaram numa visão adultocêntrica não apenas dos próprios povos investigados - que muitas vezes não reconhecem a agência infantil na organização social da comunidade -, como também permeou por

\footnotetext{
* Mestranda do Programa de Pós-Graduação em Sociologia da Universidade Federal do Maranhão - UFMA - (Imperatriz/MA/Brasil). Email: adv.jessicasousa@outlook.com

*** Docente do Programa de Pós-Graduação em Sociologia da Universidade Federal do Maranhão - UFMA (Imperatriz/MA/Brasil). Doutora em Antropologia Social pela UFSC. Email: emilenesousa@yahoo.com.br 1. Esta pesquisa está sendo realizada com bolsa de mestrado concedida pela Fundação de Amparo à Pesquisa e ao Desenvolvimento Centífıco e Tecnológico do Maranhão/FAPEMA.
} 
um bom tempo a literatura antropológica que sempre se reportava às crianças e à infância a partir das representações que delas tinham os adultos.

0 desinteresse da Antropologia em ouvir as próprias crianças, repousou, em parte, na concepção de que as crianças seriam incompetentes para falar de sua própria cultura, não tendo uma compreensão apurada das sociedades onde estariam inseridas. E essa análise leviana era produto da ideia de que existe uma cultura infantil diferente e dissociada da cultura dos adultos. Florestan Fernandes [1946] (2004) cunhou o termo culturas infantis ${ }^{2}$ defendendo que as crianças habitam uma espécie de universo paralelo em relação ao universo dos adultos, ou que elas criam, inventam uma cultura própria em relação à cultura dos adultos. Diante disso, como poderia a criança compreender ou explicar os fenômenos sociais que diriam respeito apenas aos adultos? Inúmeras pesquisas com crianças, em contextos diversificados, têm revelado a complexidade desta discussão.

Em sua experiência com a infância nos cenários camponês, indígena e em reservas extrativistas, Sousa notou que o universo adulto e o infantil encontravam-se emaranhados, de forma que as experiências de crianças e adultos poderiam ser diferentes, mas repousavam em conhecimentos dispostos a todos e aptos a serem descobertos e experimentados (SOUSA 2005, 2007, 2008).

Tassinari, pesquisando em contexto indígena, esclarece que neste lugar os uni- versos são os mesmos. tanto para adultos quanto para crianças, e que a nossa concepção ocidental de que a criança é um "vir a ser" ou "tornar-se alguém” prejudica a visão do tratamento dispensado pelos adultos indígenas às suas crianças, muitas vezes confundindo a liberdade e autonomia infantis como falta de responsabilidade dos pais (TASSINARI 2007, 2009, 2012, 2015).

Oliveira identifica a participação das crianças na Aldeia Guarani M'Biguaçu em Santa Catarina, sobretudo no tocante ao processo de valorização da tradição, o que engloba os espaços de rezas, coral e escola. Para esta autora, a presença das crianças está pautada numa noção de educação que engloba ensinar e aprender simultaneamente, quando ambos os sujeitos são considerados atuantes no processo de ensino-aprendizagem (OLIVEIRA 2005). Por sua vez, Cohn analisa a autonomia entre os Kayapó. Para este povo, as crianças aprendem tudo porque veem tudo, uma vez que possuem a possibilidade de estar em todos os lugares, bem como participam da vida cotidiana e rituais (COHN 2000).

Assim, ao contrário do que defendia Fernandes [1946] (2004), em vários contextos e culturas, os universos adulto e infantil são um só, de modo que não se pode dizer o que pertence a um repertório de conhecimentos, procedimentos ou modos infantis de experimentar o mundo em total diferença de um modo adulto.

Segundo Sousa (2018), esta crença de universos adultos e infantis separados ge-

2. "Cultura infantil, aqui, significa, aproximadamente, o mesmo que folclore infantil. A diferença entre 'folclore infantil' e 'cultura infantil' é pouco sensível. (...) A expressão 'cultura infantil' é mais adequada, na medida em que traduz melhor o caráter da subcultura que nos preocupa no momento. Ela é mais inclusiva que 'folclore infantil' e traz consigo a conotação específica, concernente ao segmento da cultura total partilhada, de modo exclusivo, pelas crianças que constituem os grupos infantis que acabamos de descrever" (FERNANDES, 2004, p. 245). 
raria a confusão que comumente se faz em torno da autonomia do universo infantil e da autonomia infantil. Para a autora,

A autonomia do universo infantil retrata esta concepção de universos de crianças e adultos separados em suas culturas. Já a autonomia infantil diz respeito ao modo como as crianças em determinadas culturas podem ser donas de uma autonomia não imaginada nem conhecida pelas sociedades urbanas, cuja noção de proteção e segurança coloca crianças de modo geral sob os olhos e cuidados permanentes dos adultos implodindo qualquer possibilidade de autonomia das crianças (SOUSA, 2018, p. 181-182).

Assim, Sousa defende que alguns modelos de infância, como a indígena, camponesa, quilombola ou de crianças quebradeiras de coco, garantiria uma maior autonomia das crianças, em um universo onde não existiria distinção entre universos infantis e adultos, ou seja, sem que houvesse uma autonomia do universo infantil.

Em outra ocasião, Sousa (2007) já havia defendido que há espaços e tempos distintos para crianças e adultos nas cidades, ao contrário do que ocorre nos contextos camponês ou indígena. Logo, haveria uma diferença entre os universos infantis e adultos nas cidades, com espaços e tempos circunscritos para adultos e crianças, com suas prescrições e proibições. Nas cidades, vislumbramos uma possibilidade de que tempos e espaços de adultos e crianças não se encontrem, o que significa uma autonomia absoluta do universo infantil, mas nem tampouco uma autonomia infantil, uma vez que as crianças estão à mercê dos adultos, dependendo deles para quase tudo.

Diante de tais afırmações, e considerando que a antropologia tem se dedicado cada vez mais a analisar a agência infantil em distintos contextos, sabendo que no contexto das cidades há muito mais uma autonomia do universo infantil do que uma autonomia infantil, esta pesquisa dedicou-se a investigar como se dava a questão da autonomia do universo infantil ou a autonomia infantil no contexto das Casas Abrigos.

No caso da Casa da Criança em análise, ainda que as crianças convivam com os adultos que ali trabalham, o universo infantil é separado do universo adulto e também de quase toda a realidade lá fora, pois geralmente elas só saem da Casa para irem à escola e à igreja. Assim, estas crianças possuem também a particularidade de, no geral, estarem separadas não só de universos adultos, mas das outras crianças lá fora ou dos outros espaços tidos como infantis.

Logo, demonstraremos como o cuidado excessivo ${ }^{3}$ do Estado com essas crianças que estavam em situação de risco em sua própria casa e foram retiradas dos pais temporariamente para ficar sob a sua tutela gera uma completa dissociação da criança com a realidade "lá fora", numa experiência com a infância restrita aos muros e portas da Casa da Criança.

Ao mesmo tempo em que esta experiência desloca os universos adultos e infantis, ela desloca também as crianças dos modos de experimentar a infância do lado de fora da Casa abrigo, por ruas e calçadas, circulando

3. Consideramos excessivo pelo fato de tudo ser acompanhado ou supervisionado por adultos, inclusive as brincadeiras. As crianças que residem na Casa da Criança são levadas para a escola por um motorista da Casa e uma das cuidadoras sociais diariamente. 
com amigos e observando a vida lá fora. Se comparadas com outras crianças que vivem com seus pais ou parentes e possuem a possibilidade de brincar na rua ou na casa dos vizinhos, dormirem na casa de familiares ou amigos e até realizarem trabalhos escolares na casa dos colegas, as crianças que vivem no abrigo estão superprotegidas e excessivamente controladas por um sistema que define tempo e espaço para tudo.

Ora, haveria espaço para uma autonomia infantil? É possível observar qualquer forma de agência entre estas crianças? Há algum protagonismo infantil? Neste artigo, revelaremos como as crianças conseguem criar estratégias para burlar o controle excessivo, a proteção e os cuidados rigorosos além do excesso de regras e imprimir alguma agência na experiência com a infância na Casa da Criança.

Esta análise refletirá sobre a situação destas crianças que, vivendo nesta Casa Abrigo, são cuidadas como em uma redoma, superprotegidas, excessivamente controladas com quase nenhum contato com a realidade lá fora. Neste contexto, reconhecemos que há uma autonomia do universo infantil, porque ele está separado não apenas de um universo adulto, mas também do universo infantil que existe lá fora, para crianças cuja rotina é marcada pela vida em família, as idas à escola sem tanta vigilância, as brincadeiras nas ruas, as conversas nas calçadas, as situações de risco inevitáveis e normais para qualquer criança que habite as grandes cidades.

Nas grandes cidades, é possível pensar não numa dissociação de um universo adulto do infantil, mas em uma autonomia relativa destes universos. No caso das crianças da Casa Abrigo pesquisada, o que nós temos é uma autonomia quase absoluta, já que a proteção e o controle excessivo privam as crianças de interagirem e conhecerem os universos adultos e até mesmo outros modos de vivenciar a infância, privando-as da experiência com a infância nas cidades como ela é experimentada por outras crianças de maneira geral.

Com base nisso é que este artigo dedica-se a uma análise da agência infantil no contexto das crianças que vivem em uma Casa Abrigo, defendendo que a agência das crianças deve ser considerada e analisada como forma de compreender os grandes sistemas ou a organização social geral das instituições em que estas crianças estão inseridas.

A noção de agência aqui adotada atribui ao ator a capacidade de processar a experiência social, e de desenhar modos de enfrentar a vida, mesmo sob as mais diversas formas de coerção. Assim, reconhecemos que os atores sociais são "detentores de conhecimento” e “capazes”, uma vez que resolvem problemas, aprendem como intervir no fluxo de eventos sociais em seu entorno, e monitoram incessantemente suas próprias ações, através da observação de como os outros reagem ao seu comportamento (Giddens, 2003).

Assim, Giddens (2003) destaca que a agência não diz respeito às intenções dos indivíduos em fazer determinadas coisas, "mas primeiramente à sua capacidade de fazer essas coisas”. A ação depende da capacidade do indivíduo de "causar uma mudança” em relação a um estado de coisas ou curso de eventos pré-existente. Isso implica que todos os atores (agentes) exercem um determinado tipo de poder, mesmo aqueles em posições de extrema subordinação. Por isso, nesta pesquisa, interessou-nos o modo como as crianças abrigadas criam estratégias para burlar o controle excessivo da casa em suas regras e imprimir sua agência no cotidiano da casa. 
0 reconhecimento da agência dos atores sociais em contextos diversos e sob algumas formas de coerção extrema obriga-nos a reconhecer que também as crianças são partícipes dos sistemas sociais em que se encontram, significando e reeditando tais sistemas. Também elas são detentoras de conhecimento (alguns próprios apenas das crianças) e capazes de atribuir significados e tecer de forma particular, entre pares ou entre gerações, as teias de relações sociais que lhe emaranham. É isso que tentaremos demonstrar ao longo deste artigo, especialmente a partir da análise etnográfica sobre a agência das crianças nesta situação de abrigo.

Esta pesquisa, realizada na Casa da Criança em Imperatriz, considera as interações com profissionais e outras instituições com as quais a Casa da Criança e seus sujeitos se relacionam, com foco nas crianças e a experiência com a infância vivenciada pelas mesmas, por isso propõe-se a compor uma etnografia nos termos de Geertz (1989), tratando-se de uma pesquisa não apenas sobre, mas com crianças.

Para que fosse possível realizar esta pesquisa, redigimos um Requerimento de $\mathrm{Au}$ torização para pesquisa na Casa da Criança e submetemos ao juiz competente pela Vara da Infância e Juventude de Imperatriz. Com isso, pudemos ter acesso ao abrigo três vezes por semana, com duração média de quatro horas em cada uma delas, além de acompanhar as crianças até as respectivas escolas.

Como técnicas, foram realizadas entrevistas com os profissionais, observação direta e participante e conversas informais com as crianças. Assim, verificamos a perspectiva das interações das crianças e como se dá a experiência com a infância entre elas, num local onde, no mais das vezes, não possuem autonomia e vivem integralmente em contexto institucional, buscando entender por meios das técnicas a serem utilizadas os seus discursos, as suas ações e as suas representações (MALINOWSKI, 1978).

\section{Infâncias citadinas: aprendizagem, ludi- cidade e segurança}

Sabemos que não há um modo homogêneo de se vivenciar a infância, mas as crianças têm experiências diferenciadas com esta fase do ciclo da vida a depender das circunstâncias em que se encontram. Logo, a infância não decorre de um conceito rígido e natural, mas é construída e, portanto, variável. Sousa (2007) argumenta:

(...) a partir do século XX, a infância é recortada de modo menos rígido, pois é vista como algo dependente da construção histórica. Assim ela ressurge como algo para cuja constituição concorrem várias forças culturais contingentes. Percebe-se então que a infância de cada criança não é algo natural e a própria ideia de "infância natural" é algo historicamente criado (SOUSA, 2007, p. 2).

Dessa forma, sempre existiram crianças entendidas como seres biológicos jovens, mas a categoria social "infância" somente foi criada na modernidade a partir dos novos tratamentos empregados pelos adultos em relação às crianças, pois até meados do século XIII estas crianças eram vistas como adultos em miniatura, com tamanho e força reduzidos (ARIĖS, 1986). Para este autor, na Idade Média “a criança mal adquiria desembaraço físico, era misturada aos adultos, partilhando de seus trabalhos e jogos" (ARIÈS, 1986, p. 10), sendo a educação fornecida através da aprendizagem, gerada no auxílio aos adultos em suas atividades.

Assim, é certo afırmar que, ao criar um conceito fechado de infância, corre-se o ris- 
co de excluir aquelas crianças cuja experiência com a infância possui características particulares, como a vivenciada pelas crianças em casas de abrigo ou de acolhimento.

A família é, no mais das vezes, o primeiro invólucro da infância, aparecendo em toda defınição de infância que se deseje universal. Ressalta-se, ainda, que o conceito de família tem se tornado cada vez mais plural para abarcar as diversas constituições familiares que têm se formado. Nas palavras de Schuch (2012, p. 3), “a família é um produto social, não é um dado natural ou universal e não pode ser pensada no singular, pois há uma pluralidade de modos de família".

Na Casa da Criança, encontramos uma representação diferenciada de família, devido ao vínculo afetivo que é gerado neste lugar. As crianças, sobretudo as que chegaram ao abrigo muito novinhas ou mesmo bebês, chamam as cuidadoras de mãe e pedem a bênção antes de dormir. Crianças maiores, mesmo não chamando as profissionais de mãe, desenvolvem afeto pelas funcionárias, a exemplo de uma menina de onze anos que foi adotada, e no momento da despedida em que partiria junto a nova família para outro estado, em meio às lágrimas, retirou um colar do pescoço e o entregou nas mãos da psicopedagoga para que não se esquecesse dela.

Logo, a ideia da família extrapola, em muito, os parentes obtidos pela consanguinidade ou afinidade, sendo pelas crianças da Casa Abrigo muito mais entendida a partir do cuidado e do afeto, uma vez que, para boa parte destas, os membros da Casa da Criança são a única família que conheceram. Por se tratar de um empreendimento etnográfico em andamento, estamos ainda apreendendo entre as crianças sobre a noção de família em seus termos para que possamos, em breve, apresentá-la. Este processo, lento e delicado, construído através de diversas técnicas, estratégias e instrumentos de pesquisa, deve nos conduzir às representações de famílias das próprias crianças.

Ora, o que dizer de crianças que foram retiradas das suas famílias - responsáveis por lhes colocar em situação de risco -, tendo sido designadas para instituições de acolhimento? Deve-se pensar na experiência dessas crianças como uma forma diferenciada e inusitada de se vivenciar a infância. Sobre a variedade de conceitos do ser criança, discorre Sousa (2005):

O significado de ser criança varia muito de um lugar para outro. Por isso, acredito que a infância é uma categoria que só está em vigor no espaço social em que é estabelecida, negociada, desestabilizada, reconstruída, e claro, legitimada. Penso até que a invenção de uma definição fechada de infância mataria a vivência da mesma, pois, qualquer tentativa de invenção de uma definição deste tipo, corre o risco de excluir crianças deste ciclo de vida (SOUSA, 2005, p. 4).

Também Castro (2007) discorre sobre as diferentes concepções de infância:

Quando falamos de infância muitas vezes nos deparamos com concepções que desconsideram que os significados que damos a ela dependem do contexto no qual surge e se desenvolve e também das relações sociais nos seus aspectos econômico, histórico, cultural e político, entre outros, que colaboram para a constituição de tais significados e concepções, que, por sua vez, nos remetem a uma imagem de criança como essência, universal, descontextualizada ou então, nos mostram diferentes infâncias coexistindo em um mesmo tempo e lugar (CASTRO, 2007, p. 3). 
Vários autores têm discutido a heterogeneidade dos modos de ser criança e de se vivenciar a infância revelada a depender do recorte analítico do pesquisador, se rural, camponês, nas cidades, quilombola ou indigena (COHN, 2005; SOUSA, 2005 2007, 2008; TASSINARI, 2007, 2009, 2012, 2015). Mas é possível, mesmo na infância vivenciada nas cidades, descobrir modos distintos de se experimentar a infância.

Por exemplo, no contexto das cidades, é possível encontrar crianças que vivenciam a infância não dentro de um lar, mas pelas ruas e calçadas, ali dormindo e realizando as demais atividades cotidianas. Em sua maioria, são crianças e famílias negras em situação de extrema pobreza ou violência. Lewis (2004, p. 235) pesquisou na cidade de Recife sobre crianças em situação de rua, e destacou que "as crianças que participaram da pesquisa são todas do gênero masculino, na maior parte negras, com idade de cinco a dezoito anos, e que deixaram o espaço doméstico para morarem na rua devido à violência familiar".

As crianças encontradas no abrigo, no mais das vezes, são compostas em maior quantidade por meninas, embora o fluxo de crianças possa alterar esse quadro. Outro dado considerável é o fato de quase todas as crianças serem negras ou pardas, além de pobres.

Sousa identificou em suas pesquisas um padrão de que a sociedade ocidental tem desenhado um modelo de infância na cidade pautada no tripé: aprendizagem, ludicidade e segurança (SOUSA, 2007). Este modelo de infância tem pouco espaço para a autonomia infantil e repousa na proteção, sobretudo, por parte da família. Em todo caso, autores da antropologia da criança têm defendido a agência e o protagonismo infantil como presentes, ainda que em menor ou maior grau, nas distintas experiências com a infância. Assim, questionamos: o que ocorre com crianças cuja experiência com a infância não tem como invólucro a família e cuja autonomia é praticamente extinta quando se vive em uma casa abrigo?

Com base nisso, partimos da hipótese de que as crianças que moram em instituições de acolhimento têm uma experiência diferenciada com a infância, uma vez que o modo como elas são inseridas ou constroem representações acerca das demais instituições responsáveis pelo processo de socialização (família, escola e igreja) é diversifıcado. Ademais, essa infância passa a ter como invólucro maior a segurança, e não a família - podendo inclusive as duas dimensões serem excludentes. Trata-se, portanto, de uma infância cujo ponto de partida para a socialização não ocorre no seio da família consanguínea, mas em uma instituição pública - na casa abrigo ou casa de acolhimento - definindo estas crianças como crianças institucionalizadas.

Acredito que o cotidiano dessas crianças encerre qualquer possibilidade de uma autonomia infantil, mantendo-as distantes do mundo lá fora e das experiências com esse mundo. Isso se agrava para as crianças cuja entrada na Casa da Criança se deu desde bebês. Noções de coletividade e individualidade, representações de lar e família são completamente diferentes daquelas construídas por crianças que crescem no seio de uma família, seja ela na cidade, no campo, ou na aldeia. Falamos dessa diferença porque, em geral, quando uma criança cresce em casa com seus pais ou parentes, estes procuram um meio de garantir a individualidade dos filhos - seja através de um presente ou objetos que pertençam apenas à criança -, fato que não ocorre com as crianças que vivem no abrigo, local onde 
tudo é de todos, a exemplo de roupas e calçados, que são de uso coletivo.

\section{No caminho para o abrigo}

Décadas atrás, as crianças sequer eram vistas como sujeitos de direitos e deveres, sendo totalmente submissas ao julgo que já carregava seus pais. Hoje, entretanto, podemos afırmar que a infância é um período decisivo na formação moral e psíquica de uma pessoa, e pode ser vivenciada de diversas maneiras. Inclui-se a participação da escola nesse desenvolvimento, onde a criança se socializa com adultos e outras crianças. Cada família, com seus costumes e valores, disponibiliza para suas crianças uma forma de desfrutar da infância. Fala-se, então, em heterogeneidade nas vivências da infância. Assim, descreve Sarmento (2005):

As condições sociais em que vivem as crianças são o principal factor de diversidade dentro do grupo geracional. As crianças são indivíduos com a sua especificidade biopsicológica: ao longo da sua infância percorrem diversos subgrupos etários e varia a sua capacidade de locomoção, de expressão, de autonomia de movimento e de acção etc. Mas as crianças são também seres sociais e, como tais, distribuem-se pelos diversos modos de estratificação social: a classe social, a etnia a que pertencem, a raça, o género, a região do globo onde vivem. Os diferentes espaços estruturais diferenciam profundamente as crianças (SARMENT0, 2005, p. 370).

Bom, se os diferentes espaços estruturais diferenciam as crianças, como defende Sarmento, torna-se necessário pensar no sentido da infância institucionalizada. Por institucionalização pode-se utilizar a conceituação de Afonso (2014):
"Institucionalização" é um conceito simultaneamente psicossocial e jurídico-legal. Assim, refere-se à mudança de "ecologia de desenvolvimento" decidida por uma autoridade legal. A institucionalização consiste na suspensão da guarda parental e consequente acolhimento institucional de crianças e jovens que se encontram em situação de perigo, considerando-se que há uma situação de perigo quando se verifica a ocorrência de várias situações de risco numa mesma criança ou jovem, podendo manifestar-se de várias formas, legalmente definidas (vide Lei nº147/99, de 1 de setembro, Lei de Proteção de Crianças e Jovens em Perigo) (AFONSO, 2014, p. 10).

Cumpre ressaltar, também, que a permanência na instituição é temporária. Sobre a durabilidade da estadia, também comenta Afonso (2014):

0 acolhimento institucional quando é de curta duração (geralmente não superior a seis meses) tem lugar em "Casa de acolhimento temporário”, podendo tornar-se de longa duração quando não há a possibilidade imediata de retorno à família. Quando o acolhimento é prolongado tem lugar em "Lar de infância e juventude" e, nestas circunstâncias, o acolhimento é superior a seis meses. A instituição de acolhimento de menores tem como objetivos prevenir, intervir, remediar e contribuir para a melhoria da vida da criança e da sua família. Este tipo de instituição visa também proteger o menor de abuso, negligência e exploração (AFONSO, 2014, p. 10).

Cabe alertar que não se pode confundir instituição de acolhimento (ou abrigo), com orfanato. Enquanto na instituição de acolhimento as crianças são retiradas do seio familiar pelo Poder Público ao ser consta- 
tada situação de risco ou vulnerabilidade, o orfanato é entendido como sinônimo de caridade, e remete a um local que recebe crianças cujos pais não querem ou não podem criá-las, entregando-as voluntariamente para que sejam cuidadas ou possam conseguir outra família (GUEDES, 2013).

Nazario (2015), em seu trabalho "Entre estar na casa e estar em casa: modos de ser criança em um contexto de acolhimento institucional", analisou uma Casa (Lar) de Santa Catarina. Nesse contexto, buscou analisar a percepção de estar na casa (visão dos adultos que ali trabalhavam) e estar em casa (visão das crianças que ali viviam). Para tanto, observou a Casa como instituição - repleta de regras e rotina - e como lar - onde crianças brincavam e desenvolviam vínculos. Nesse estudo, Nazario (2015) conclui a forma própria das crianças de ultrapassarem algumas regras da institucionalização e criarem suas utilizações próprias, traduzindo um sentimento de estar em casa (por exemplo, a destinação dos quartos que, em vez de serem utilizados apenas para dormir, o são para brincar).

Por sua vez, Santos (2013) realiza uma pesquisa bibliográfica sobre as mudanças na história brasileira no tocante ao acolhimento institucional. Ela descreve como o abrigo possuiu, durante muito tempo, caráter essencialmente assistencialista, pouco se preocupando com o desenvolvimento das crianças e adolescentes. Entretanto, conclui a autora que, com as mudanças sociais e culturais e o consequente advento do Estatuto da Criança e do Adolescente, o acolhimento institucional passou a visar ao retorno familiar da criança abrigada, bem como a ter um olhar mais amplo sobre as crianças, as famílias e a comunidade, apesar de não ter suprimido totalmente os antigos problemas.
A partir dos conceitos e discussões sobre crianças abrigadas ou institucionalizadas, infância e proteção infantil, esta pesquisa pretende analisar a experiência com a infância na Casa da Criança em Imperatriz. Para tanto, dialogará com conceitos do Direito e da Sociologia da Infância, e se utilizará de métodos e técnicas de pesquisa da Antropologia da Criança para uma investigação instigante sobre a infância em situação de abrigo.

\section{Crianças abrigadas e a Casa da Criança de Imperatriz}

Sabe-se que a criança é um ser ainda em desenvolvimento, sendo por isso considerada vulnerável, social e juridicamente, constituindo dever de todos (família, Estado e sociedade) protegê-las. Assim assegura o Estatuto da Criança e do Adolescente:

Art. 30 A criança e o adolescente gozam de todos os direitos fundamentais inerentes à pessoa humana, sem prejuízo da proteção integral de que trata esta Lei, assegurando-se-lhes, por lei ou por outros meios, todas as oportunidades e facilidades, a fim de lhes facultar o desenvolvimento físico, mental, moral, espiritual e social, em condições de liberdade e de dignidade.

A instituição família, apesar de possuir a possibilidade de ser constituída de formas variadas - inexistindo assim um conceito universal, segundo Cláudia Fonseca (2005, p. 52), que afırma que "a própria noção de família varia conforme a categoria social com qual estamos lidando" -, pode ser considerada uma das bases de uma sociedade, na qual seus componentes são responsáveis por transmitir seus costumes e princípios às suas crianças, dando o pontapé inicial no processo de so- 
cialização. Se nesse processo há falhas e as crianças, ao invés de serem educadas e protegidas, são expostas a riscos e situações perigosas, o Estado deve atuar de forma a fornecer essa proteção.

Assim, como forma de atuação conjunta de Estado e sociedade, surgem as instituições de acolhimento para crianças nestas circunstâncias. Nesse momento, as crianças são abrigadas, e a guarda dos pais é deliberada na justiça. Desse processo, pode-se resultar em dois vieses: a situação pode ser regularizada e os pais retomarem a criança para si, ou os pais podem perder o direito parental e as crianças serem postas para adoção. Durante o trâmite legal, as crianças são colocadas em instituição de acolhimento, como a Casa da Criança, em Imperatriz.

Tratando-se de uma instituição de acolhimento, a Casa da Criança de Imperatriz conta com a organização de uma rotina para realização das tarefas pelas crianças. Há horário para lanchar, brincar e banhar, por exemplo. Onde fica, portanto, o protagonismo da criança no estabelecimento de seu dia-a-dia?

A Casa da Criança é uma instituição de muito valor, pois além de acolher as crianças que não se encontravam em um lar feliz, encontramos pessoas de bom coração que dão a elas amparo e cuidado (Depoimento de pais adotivos - trecho retirado da Cartilha da Casa da Criança, ainda não publicada).
Trata-se, portanto, de uma instituição de acolhimento para crianças com faixa etária de 0 a 8 anos $^{4}$ que se encontravam em situação de risco - por abandono ou violência - ou extrema pobreza, a qual visa a assegurar as diretrizes do Estatuto da Criança e do Adolescente, bem como orientações da Vara da Infância e Juventude de Imperatriz, Secretaria de Desenvolvimento Social do Município e dos Conselhos e Protocolos de Referência Nacional.

A faixa etária e a possibilidade de permanência após a idade estabelecida, bem como o fato de prezarem pela união dos grupos de irmãos, lembram-nos da pesquisa de Nascimento (2014, p. 278) com as crianças indígenas Kaiowá que vivem em um abrigo no Mato Grosso do Sul, ao informar que:

O Lar de Crianças Santa Rita de Cássia é uma instituição filantrópica, administrada pela União Espírita de Dourados, que atua no acolhimento de crianças de 0 a 7 anos de idade, mas que podem permanecer na instituição até os 12 anos e, dependendo do bom comportamento, essa idade máxima de permanência na instituição pode se estender um pouco mais. Esse é o único abrigo que acolhe meninos e meninas, pois atua no modelo de lar comunitário, as chamadas casas/lares, e, por isso, tem a possibilidade de não separar irmãos dentro dessa faixa etária (NASCIMENTO, 2014, p. 278).

4. Excepcionalmente, são abrigadas crianças com faixa etária superior à permitida (encontramos crianças com até 13 anos), em virtude dos grupos de irmãos que são recebidos na Casa da Criança. Isso porque o abrigo preza por manter os irmãos juntos, a fim de não lhes submeter a mais uma violência emocional. 5. Informação retirada da Cartilha da Casa da Criança (não publicada, mas disponível em via impressa na secretaria do abrigo), motivo pelo qual não constam mais detalhes acerca desta senhora. 
Retornando às informações do abrigo aqui pesquisado, a Casa da Criança é fruto de uma ideia discutida em 1995 quando uma senhora chamada Dulcimar ${ }^{5}$ abrigou em sua residência 03 crianças; contudo, sua implementação e consequente funcionamento deu-se entre 1997 e 1998, sendo denominada Casa de Passagem. Hoje a Casa da Criança é mantida pelo município de Imperatriz em parceria com o Poder Judiciário da mesma, sendo de responsabilidade da Secretaria de Desenvolvimento Social (SEDES) do município, e é considerada uma das melhores instituições de acolhimento do Brasil. Durante a realização da pesquisa, o abrigo estava acolhendo 25 crianças, das quais a maioria era de meninas (sendo 5 dessas crianças com mais de 8 anos de idade em razão dos grupos de irmãos), mas seu espaço físico possui capacidade para acolher até 45 crianças.

A instituição conta com uma equipe multidisciplinar para acompanhamento do desenvolvimento infantil, tais como psicóloga, enfermeira, assistente social e pedagoga. Nesse sentido, dispõe Calza e Carniel (2018), ao tratar do Sistema de Garantia dos Direitos da Criança e do Adolescente (SGD), cujos parâmetros estão definidos da Resolução $n^{\circ}$ 113, de 19 de abril de 2006, do Conselho Nacional dos Direitos da Criança e do Adolescente (CONANDA):

(...) nota-se que compõe a rede de proteção à criança e ao adolescente um conjunto interinstitucional e amplo de órgãos, entidades, programas e serviços destinados ao atendimento de crianças, adolescentes e suas respectivas famílias constituído por profissionais das mais diversas áreas, com diversificados históricos de vivências e formações - a exemplo de conselheiros de direitos, conselheiros tutelares, gestores e profissionais das áreas da saúde, assistência social, educação, segurança pública, cultura, esporte, lazer, trabalho, dirigentes e profissionais de entidades não governamentais da sociedade civil, profissionais do sistema de justiça (de tribunais e promotorias de justiça, defensorias públicas, delegacias especializadas), entre outros (CALZA E CARNIEL, 2018, p. 2).

Ao chegarem à Casa, as crianças trazem consigo conhecimentos de mundo de forma particular, em decorrência do meio em que estavam inseridas e das situações que vivenciaram. Ao analisar a experiência com a infância por estas crianças, serão considerados os saberes e as experiências que precedem a chegada à casa abrigo, no caso das crianças maiores. Conhecimentos de mundo versus conhecimentos adquiridos na instituição serão contrapostos nesta investigação. Isso é importante por partimos da hipótese de que estas crianças, uma vez inseridas na casa abrigo, passam a experimentar uma situação de superproteção em comparação às crianças com as quais convivem na escola ou na igreja e que crescem no seio de suas famílias. A atenção às experiências anteriores e suas trajetórias antes da casa de acolhimento podem revelar importantes aspectos da socia-

9. Não seria verdadeira a tese de que Wright Mills e Karl Mannheim seriam relativistas. Os dois combateram o relativismo nas ciências sociais, podendo-se questionar em que medida eles obtiveram êxito. Seria importante mencionar que algumas ideias desenvolvidas nesta parte do trabalho se devem ao exame dos comentários críticos de Irving Louis Horowitz, C. Wright Mills: an American utopian, New York, The Free Press, 1983, p. 117-134. 
lização destas crianças e da sua experiência com a infância na Casa da Criança.

Assim, é preciso destacar que este período é um período de espera, em que a criança e a experiência com a infância que era vivida em casa, no seio de uma família, estão em suspenso. Só depois de cumprido este tempo e definida as circunstâncias em que se encontra a sua família, ela poderá retornar para sua família ou seguir para o processo de adoção.

Há também que se ressaltar o fato de o surgimento do termo abrigo ter acontecido com o Estatuto da Criança e do Adolescente (ECA), sendo utilizado para definir as instituições que acolhem e protegem as crianças em situação de risco pessoal ou social, como dispõe Prada e Weber (2006):

Abrigo é o nome dado a instituições que têm por objetivo acolher e proteger crianças em situação de risco pessoal e/ou social, ou seja, "violados ou ameaçados em seus direitos básicos, seja por ação ou omissão do Estado, pela falta, omissão ou abuso dos pais/responsáveis, ou em razão da própria conduta" (Carvalho, 1993, p.18). Uma ressalva importante a ser feita é sobre o uso dos termos abrigo, abrigamento, instituição e institucionalização. 0 termo abrigo é relativamente recente, nasce juntamente com o início das discussões e formulações do ECA (década de 1980). 0 termo mais comumente utilizado antes deste período era simplesmente "instituição" para crianças abandonadas, carentes, enfım, em situação de risco pessoal ou social. 0 processo de abrigamento destas crianças era chamado institucionalização (PRADA E WEBER, 2006, p. 2).

A razão pela qual as crianças são retiradas de suas famílias é, via de regra, por estarem em situações de risco, quando através de intervenção dos Poderes Públicos, seja por meio de denúncia pública ou constatação direta do Conselho Tutelar, elas são encaminhadas ao abrigo.

Tendo situação de risco como termo muito abrangente, Cruz (2007) exemplifica quais podem ser tais situações, conforme se observa:

A negligência dos pais tem despontado como motivo de ingresso mais freqüente em entidades de abrigo. A nível nacional, o recente Levantamento Nacional dos Abrigos (Silva, 2004) aponta que, entre os principais motivos de abrigamento, está a carência de recursos materiais da família $(24,1 \%)$; o abandono pelos pais ou responsáveis $(18,85)$; a violência doméstica $(11,6 \%)$; a dependência química de pais ou responsáveis $(11,3 \%)$ e a vivência de rua (7\%) (CRUZ, 2007, p. 1).

Desta forma, inúmeros são os motivos que podem expor o menor a perigo, cabendo a quem é de dever protegê-lo, defender seus direitos e garantir uma boa formação moral. Se não for a família, que seja então o Estado e suas autoridades competentes. Portanto, após análise do Poder Judiciário em devido processo legal, se ficar sentenciada a perda do direito parental pela família original, a criança é posta em adoção.

Nota-se, então, uma parceria sociedade-Estado atuando em prol dos direitos das crianças, com um trâmite processual dividido em várias etapas, contando com a participação dos adotantes interessados, magistrado, equipe multiprofissional e, inclusive, a própria criança. Trata-se da famigerada burocracia, tratada por Correa (2018) como um exemplo de tecnologias de governo em ação.

A perspectiva teórica conceitual utilizada considera, em particular, a burocracia co- 
mo uma das diversas tecnologias de governo para se pensar as engrenagens do estado em seus diversos níveis, tendo em vista a dinâmica que envolve tanto aparatos organizacionais quanto interações cotidianas que envolvem as famílias, funcionários da burocracia estatal e dos conselheiros tutelares (CORREA, 2018, p. 03).

Correa (2018), no mesmo sentido, comenta a importância de agregar forças nesses processos.

Pensar sobre a noção de tecnologias de governo implica em considerar formas de intervenções possiveis a partir de um agregado de forças, sejam elas legais profıssionais, administrativas, orçamentárias; técnicas de implementação (capacitação, execução, avaliação) e conhecimentos autorizados cunhados para regular as decisões (CORREA, 2018, p. 03).

Portanto, todas as atividades que envolvam a Casa da Criança necessitam de profissionais devidamente instruídos para que cada ação não gere dano ainda maior aos menores que deveriam ser protegidos.

\section{Autonomia das Crianças versus contro- le institucional}

Neste item, reunimos situações que identificamos no abrigo e estão ligadas ao processo de autonomia. Para tornar mais didática a reflexão, fizemos uma divisão em três vieses: situações nas quais não há qualquer forma de autonomia por parte das crianças, prevalecendo aquilo que é estipulado pelos adultos; situações em que há uma aparente autonomia, na qual as crianças podem escolher, mas somente dentro do leque de opções designado pela instituição; e situações nas quais as crianças de fato exercem seu poder de escolha.

\subsection{Quando não há autonomia}

Há na Casa da Criança situações em que as crianças não conseguem exercer qualquer tipo de autonomia. Trata-se de episódios rotineiros, nos quais se verifica uma série de imposições dos adultos sobre as crianças, devendo estas simplesmente acatá-las.

A Casa conta com um quadro de rotinas que estabelece o horário e a atividade a ser realizada. Por exemplo, o quadro dispõe que as crianças devem tomar banho às 06h10 (antes do café da manhã), 10h40 (após o momento lúdico da manhã), 11h40 (antes do almoço e da ida à escola), 17h30 (após brincadeiras no pátio). Se elas desejam tomar banho em algum momento diferente, via de regra não é permitido, apenas em situações excepcionais. Também, as idas e vindas da escola possuem horário determinado e acompanhamento do motorista e cuidadores, não existindo possibilidade de irem à casa dos demais coleguinhas de classe ou brincarem por um tempo após o término da aula.

Um ponto que destoa dos demais tipos de infância vivenciadas na cidade é o fato de que a infância vivenciada no abrigo, um lugar isolado dentro da cidade, é marcada por falta de opções em muitos aspectos. A refeição constitui um exemplo visível, visto que nesse ambiente as crianças devem comer o que lhes é servido. Não há como apontarem o que gostam ou não de comer. Por exemplo: muitas crianças não gostam de comidas cozidas, mas se esta é a refeição servida, elas consomem, caso contrário, ficarão com fome até a próxima refeição.

Outro aspecto a ser considerado é que, de modo geral, é comum que crianças escolham 
qual roupa desejam vestir ao longo do dia ou para passear, o que não ocorre na Casa da Criança. Ali, as roupas são de uso coletivo, e diariamente as funcionárias determinam quem vai vestir o quê, cabendo à criança apenas acatar tal determinação, não podendo fazer uso de suas preferências pessoais.

\subsection{Quando a autonomia é apenas aparente}

Por sua vez, a escolha das escolas nas quais cada criança estudará é feita pela equipe de profissionais do abrigo, bem como se a matrícula ocorrerá para o turno matutino ou vespertino. De hábito, é realizado um fórum com a pedagoga da Casa da Criança a cada 03 meses, consistindo em análise dos boletins e conversas com as crianças e seus professores. Nesse aspecto, encontramos outra forma do exercício da autonomia infantil nesse contexto institucional, pois as crianças - em especial as maiores - já perceberam que há uma forma de se voltarem contra a decisão que lhe é imposta: tornando-se desleixadas e, consequentemente, diminuindo o rendimento escolar. Isso porque uma vez que a criança não se adapte à escola na qual foi matriculada - seja por não ter conseguido estabelecer uma relação com os professores, seja por não ter se adaptado aos colegas, por exemplo - e passa a desenvolver um baixo rendimento ou rejeição ao contexto escolar, ela pode solicitar à pedagoga do abrigo que a troque de escola.

Geralmente as crianças solicitam serem matriculadas onde outro colega do abrigo já esteja estudando, citando os nomes das escolas desejadas. Trata-se de uma estratégia para permanecer por mais tempo ao lado de seus amigos, pois estudando no mesmo turno e estabelecimento de ensino, também retornarão juntos para a Casa, o que permite as brincadeiras no transporte oficial.
0 conhecimento do nome da instituição de ensino é obtido através das idas e vindas à escola no veículo que utilizam diariamente, demonstrando que elas permanecem alerta em todo o trajeto e tomam para si ciência das informações que lhes são úteis, como o nome dos colégios onde seus amigos estudam. Essa solicitação é analisada e, frequentemente, aceita, pois com a mudança há um aumento no rendimento escolar. Ressalta-se que essa alteração só é feita se também for benéfica ao abrigo, não atrapalhando o trajeto, por exemplo.

Outro caso de autonomia aparente trata sobre a possibilidade de que as crianças realizem atividades extraescolares. Tal possibilidade ocorre em virtude da existência de bolsas ofertadas pela comunidade que conformam um rol de opções para as crianças: estudo de língua estrangeira, prática esportiva, aprendizagem de instrumentos musicais e até mesmo de canto/coral. Após esforço das funcionárias para aquisição dessas bolsas, é comunicada às crianças a existência desse acervo, para que possam escolher se/e de qual atividade extraescolar desejam participar, revelando assim sua autonomia no processo.

Durante a pesquisa, constatou-se a prática de aulas para aprendizagem de instrumentos (violão e flauta) por três crianças e aulas de canto/coral por outras duas crianças. Além disso, elas contam com apoio de uma escola particular da cidade, SESI, que oferta colônias de férias de forma gratuita para as crianças do abrigo, podendo elas escolherem se desejam ou não participar.

No que diz respeito ao material escolar, destaca-se que seu fornecimento pode ocorrer de duas maneiras distintas: através do município - por meio da Secretaria de Desenvolvimento Social (SEDES) - ou por doações da comunidade. No primeiro caso, 
o material é comprado em grande quantidade e possui qualidade inferior, consistindo no essencial, tal como caderno e lápis, com design padronizado. Assim, o material é idêntico e não há qualquer possibilidade de escolha. Entretanto, no que se refere às doações feitas pela comunidade, observa-se que os produtos são de uma melhor qualidade e maior variedade. Nesse caso, é dado às crianças o direito de escolha, mas dentro de opções pré-determinadas, tratando-se de uma escolha limitada. Não apenas isso, mas se recebem algum produto com características conhecidas por agradar alguma criança específica - cor de rosa, por exemplo - as funcionárias o separam para essa criança, mesmo sem questioná-la se é realmente isso o que ela quer, também retirando dos demais a possibilidade de tê-lo. Ainda, as crianças se aproveitam das visitas de terceiros para uma tentativa de conseguirem algo específico, como ocorreu com a pesquisadora ao lhe pedirem uma caneta de quatro cores igual a que ela utilizava.

\subsection{Quando há autonomia por parte das crianças}

Uma primeira consideração da autonomia de fato exercida pelas crianças na Casa repousa no fato de que as crianças maiores ${ }^{6}$, advindas de um lar no qual tinham sobre si a responsabilidade consigo mesmas e com seus irmãos menores, à revelia da rotina que lhes é imposta, participam dos afazeres domésticos. Assim, costumam cuidar da organização das cadeiras para a realização das refeições, bem como ajudar na separação das frutas e demais alimentos para o lanche, puxar a água do chão do banheiro após os constantes banhos, e procurar as "tias" da Casa para que lhes auxiliem na execução das atividades escolares. Ressaltando que tais ações ocorrem de forma espontânea, sem que estejam previstas nas inúmeras tabelas fixadas pelas paredes da Casa.

Percebe-se que não há regras na Casa acerca da execução ou não de atividades domésticas por parte das crianças, mas estas conseguem se afastar da redoma que lhes é sobreposta e resgatar uma espécie de agência que possuíam no antigo lar. Em contrapartida, eventualmente recebem das funcionárias da Casa, agradecidas pela ajuda, recompensas em forma de pequenos mimos. Esses presentinhos são variados, mas normalmente consistem em lacinhos de cabelo e, certamente, animam as crianças a continuarem contribuindo com as atividades domésticas.

No que se refere ao universo lúdico, espaço no qual deveríamos encontrar maior liberdade por parte das crianças, constatou-se que há imposição por parte das funcionárias no modo como as mesmas devem desfrutar do momento. Nesse contexto do abrigo, na sala de lazer (espaço que funciona ao mesmo tempo como biblioteca/brinquedoteca/ sala de vídeo), as crianças podem escolher qual filme desejam assistir, mas não podem escolher se querem ou não assistir. Quando mudam o foco, escutam a seguinte frase: "Menino (a), senta e assiste!"

Contudo, há um meio de burlar o controle excessivo nesse momento que deveria ser divertido e exercer sua autonomia através da esperteza infantil (característica inerente aos atores sociais que são): quando

6. Referimo-nos aqui, como regra, às crianças com faixa etária a partir dos 7 (sete) anos de idade, podendo haver exceções. 
há visitas na Casa. As crianças aproveitam quando há a presença de terceiros no espaço para finalmente brincarem sem serem chamadas a atenção. Correm, pulam, brincam de pega-pega... Foi exatamente o que fizeram durante a presença da pesquisadora e de outros visitantes.

Crianças têm necessidade de brincar e explorar o universo, visto que tudo consiste em algum tipo de novidade. Portanto, além dos momentos lúdicos internamente, há passeios através dos quais as crianças obtêm conhecimento de outros pontos da cidade, tais como cinema, visitas aos shoppings e passeios ao ar livre - sobretudo na Beira-Rio e praças, espaços que contam com pequenos parques e brinquedos. Esses passeios são realizados com uma frequência de, pelo menos, uma vez ao mês, e sempre são acompanhados por algum funcionário da Casa, sendo que na maioria das vezes esse acompanhamento é realizado pela pedagoga.

Nesses casos, pode-se constatar o exercício da autonomia por parte das crianças no processo de escolha do local a ser visitado. Não somente isso, mas essa decisão envolve também outra característica fundamental: o desenvolvimento da noção de coletividade. Isso porque as crianças precisam chegar a um acordo sobre o destino do passeio, prevalecendo a vontade da maioria em detrimento do desejo da minoria. Entretanto, ainda que livres para escolherem o destino, continuam com uma redoma sobre si durante o passeio, não tendo total liberdade para explorarem o local.

Diante do exposto, passo a descrever, talvez, a maior prova de autonomia encontrada na pesquisa na Casa da Criança, embora tratemos aqui de uma exceção: o desejo de estar ou não na Casa. Durante a pesquisa, nos deparamos com um caso peculiar de uma criança que fugiu da casa dos pais biológicos e procurou refúgio no abrigo - pela segunda vez.

Seu primeiro contato com a Casa da Criança foi através de denúncia de suposto espancamento por parte da avó, momento em que o Conselho Tutelar efetivou a institucionalização durante o período de investigação. Após detalhada apuração, constatou-se que não houve qualquer espancamento, portanto, o caso não consistia em situação de risco, momento em que restituíram a criança à família. Trata-se de um caso em que a criança - ressalta-se novamente que a criança é um ator social, e como tal munido de uma visão própria das coisas ao seu redor - tomou ciência da existência da Lei 13.010/2014, conhecida informalmente como Lei da Palmada, e sempre que a avó lhe castigava, ainda que de forma branda, a criança fugia e buscava proteção no abrigo. Isto porque, conhecendo crianças que passaram a morar lá e tendo estado lá uma vez, gostaram da vida no abrigo e criavam estratégias constantemente para voltar a ele. Da segunda vez, a criança não só fugiu como levou consigo o irmão mais novo. Ao chegarem ao abrigo, e as funcionárias ouvirem as queixas, não encontraram outra alternativa a não ser proceder à institucionalização. Ainda não foi definido o desenrolar desse caso, mas a avó frequentemente vai até o abrigo, em prantos, em busca dos netos.

Essa é uma curiosa situação através da qual se torna nítido como crianças fazem leituras específicas da realidade e da vida à sua volta, exercendo autonomia - que é trazida do próprio lar - desde as formas mais simples até em escolhas que mudarão o rumo das suas vidas. A autonomia desta criança do exemplo é dada no caminho para o abrigo e não lá, em suas dimensões.

Portanto, na Casa da Criança predomina a imposição dos adultos sobre as crianças, 
mas estas conseguem burlar determinadas regras e encontrar espaço para exercerem sua autonomia nos processos de escolha. Por serem crianças vindas de situações de risco, o Estado as coloca numa redoma para serem protegidas, o que justifica a presença constante de profissionais com as crianças onde quer que estejam. Entretanto, por também serem crianças advindas de lares onde exerciam a própria responsabilidade consigo mesmas, desempenhando muitas vezes o papel de filhos, pais e cuidadores de si próprias, essa proteção institucional reveste-se de um controle excessivo, e retira delas a possibilidade de agir como desejarem, tal como eram acostumadas. Diante disso, encontramos uma linha tênue e questionamos que objetivo tem o abrigo e que força rege tal espaço: se a proteção ou o controle.

\section{Considerações Finais}

Com o objetivo de analisar a construção da autonomia infantil por crianças em situações de abrigo, este artigo partiu da hipótese de que instituições de acolhimento infantil são espaços cuja organização repousa no excesso de regras e controle de tempo/ espaço/ações, não deixando lugar para a agência infantil. Todavia, as crianças criam estratégias para garantir sua autonomia, burlando as regras estipuladas.

Para tanto, partimos de uma discussão sobre a complexidade do fazer antropológico em relação às crianças, não as considerando como capazes de compreender a sociedade na qual estão inseridas. Isso ocorre porque, desde Florestan Fernandes [1946] (2004) e sua defınição de culturas infantis, entendeu-se que as crianças habitam uma espécie de universo paralelo em relação ao universo dos adultos. Entretanto, autores como Sousa (2018) e Tassinari (2007, 2009,
2012, 2015), entendem que, embora a experiência de crianças e adultos possa ser diferente, repousa em conhecimentos que parecem estar à disposição de todos para serem descobertos e experimentados.

Transformando as terminologias autonomia infantil e autonomia do universo infantil em categorias sociológicas, consideramos que em comunidades indígenas e rurais, por exemplo, há uma maior autonomia das crianças, em um universo onde não há distinção entre ambientes infantis e adultos. Por sua vez, a infância vivenciada nas grandes cidades diferencia os espaços e tempos circunscritos para adultos e crianças, produzindo universos relativamente autônomos, mas dificultando a autonomia infantil.

Em seguida, passamos a uma definição de criança institucionalizada ou abrigada, conforme Afonso (2014), sendo aquela criança em situação de risco que sofreu suspensão da guarda parental e consequente acolhimento institucional. Ainda, definimos Casa Abrigo, a partir dos autores Prada e Weber (2006), como instituições que têm por objetivo acolher e proteger crianças em situação de risco pessoal ou social, diferenciando-as de orfanato.

Por fim, trouxemos situações que nos pareceram reveladoras da dicotomia Autonomia Infantil versus Controle Institucional, tal como a imposição da escola onde a criança é matriculada e a sutil descoberta por esta mesma criança de uma tática para voltar-se contra a imposição e conseguir mudar para a escola de algum amigo; ou como se aproveitam da presença de terceiros para burlarem a regra das tias de "sentar e assistir”, transformando o momento do filme em momento de brincadeiras sem serem chamadas atenção pelas funcionárias.

Concluímos, assim, que no caso da Casa da Criança de Imperatriz, o Estado, respon- 
sável por mudar o destino da vida dessas crianças, ao retirá-las de suas famílias onde viviam em situações de risco, e, com a intenção de protegê-las e também proteger a si próprio no desempenho de suas atividades, termina por exceder-se no controle em determinadas situações, colocando as crianças em uma espécie de redoma, sendo monitoradas em tempo integral e tendo alguém para fazer todas as suas escolhas, a exemplo de suas vestimentas, situação conflitante com o ritmo de vida com o qual eram acostumadas, tomando conta de si próprias, o que as leva a criar estratégias para exercer sua autonomia, ainda que de forma esporádica.

Por um lado, entendemos que no caso de crianças em situações de risco, o Estado cumpre a sua função ao resguardá-las e protegê-las sob a sua tutela. Por outro lado, analisamos que, uma vez retiradas de suas casas e sob a proteção do Estado, podemos perceber certos excessos por parte da Casa da Criança, instrumento do poder público, para protegê-las. Tal compreensão nos levou à reflexão sobre que instituto rege a Casa da Criança, se a proteção ou o controle. E ainda que consideremos a proteção como fim maior, perguntamo-nos se esta proteção institucional excessiva é realmente em defesa das crianças ou da própria Casa Abrigo, no empenho de suas funções.

\section{Referências}

ARIÈS, P. História social da Criança e da Família. 2a edição. Rio de Janeiro: Guanabara,1986.

BRASIL. Lei no 8.069, de 13 de julho de 1990. Dispõe sobre o Estatuto da Criança e do Adolescente. Brasília, 13 de julho de 1990. Disponível em: <http://www.planalto.gov.br/ccivil_03/LEIS/ L8069.htm>. Acesso em: 06 jan. 2017.
AFONSO, S. A. T. Processos de resiliência, regulação emocional e perspectiva temporal: um estudo comparativo sobre adolescentes institucionalizados vítimas de maus-tratos familiares. Universidade Portucalense, Portugal. 2014 (Dissertação de Mestrado). Disponível em <http://repositorio. uportu.pt:8080/bitstream/ 11328/938/2/TMPS\%20 33_Disserta\%C3\%A7\%C3\%A30\%20de\%20Mestrado\%20-\%20Susete\%20Afonso.pdf> Acesso em 10 nov. 2018.

CALZA, L. C.; CARNIEL, F. A promessa da infância protegida: uma etnografia das práticas de documentação do Sistema de Garantia dos Direitos da Criança na região metropolitana de Maringá. 31 a Reunião Brasileira de Antropologia (RAM), dez. 2018. Disponivel em <https://www.31rba.abant. org.br/arquivo/downloadpublic?q=YToyOntzOjY6InBhcmFtcyI7czozNToiYToxOntzOjEwOiJJRF9BUlFVSVZPIjtzOjQ6IjIwMzUi030i03M6MToiaCI7czozMjoiNWNkNjkyNzVhNWJkMTkzZmU1ZmJkNjk3NzJlZGY3ZmMi030\%3D> Acesso em 26 fev. 2019.

CASTRO, M. G. B. de. Noção de criança e infância: diálogos, reflexões, Saberes de Infâncias e a Formação de Professores Indígenas interlocuções. In: COLE - CONGRESSO DE LEITURA, UNICAMP, 2007. P. 1-11

COHN, C. "Crescendo como um Xikrin: uma análise da infância e do desenvolvimento infantil entre os Kayapó-Xikrin do Bacajá”. In: Revista de Antropologia. São Paulo: USP, 2000. Vol.43, n 2, pp. 195-222.

Antropologia da

Criança. Rio de Janeiro: Jorge Zahar (Coleção Passo a Passo; 57). 2005.

CORREA, R. M. S. Famílias em ação: construindo estratégias e cruzando caminhos de políticas de acesso à creche em Porto Alegre. 31 ${ }^{\mathrm{a}}$ Reunião Brasileira de Antropologia (RAM), dez. 2018. Disponivel em <https://www.31rba.abant.org.br/ arquivo/downloadpublic?q=YToyOntz0jY6InBhcmFtcyI7czozNToiYToxOntzOjEwOiJJRF9BUIFVSVZPIjtzOjQ6IjIzNDEi030i03M6MToiaCI7czozMjoiYmMxZTkxZjE5MGZiNzU1NmIyY2E2YzQwNGIwMWIyMDQi030\%3D> Acesso em 25 fev. 2019. 
CRUZ, L. R. da. Infância abrigada: negligências e riscos no campo das políticas públicas. Psicol. Am. Lat., México, n. 9, abr. 2007. . Disponível em <http://pepsic.bvsalud.org/scielo.php?script=sci_arttextetpi$\mathrm{d}=$ S1870-350X2007000100004\&lng=pt\&nrm=iso>. Acesso em 03 nov. 2018.

FERNANDES, F. [1946]. As trocinhas do bom retiro: contribuição ao estudo folclórico e sociológico da cultura e dos grupos infantis, In: Folclore e Mudança Social na cidade de São Paulo. São Paulo: Martins Fontes, 2004.

FONSECA, C. Concepções de família e práticas de intervenção: uma contribuição antropológica. Saúde soc., São Paulo, v. 14, n. 2, p. 50-59, ago. 2005. Disponível em <http:// www.scielo.br/scielo.php?script=sci_arttextetpi$\mathrm{d}=$ S0104-12902005000200006\&lng=enctnrm=iso>. Acesso em 15 nov. 2019.

GEERTZ, C. A Interpretação das Culturas. Rio de Janeiro: Editora Aplicada, 1989.

GIDDENS, A. A constituição da Sociedade. 2 ed. São Paulo: Martins Fontes, 2003 (Biblioteca Universal).

GUEDES, C. F. Acolhimento institucional na assistência à infância: reflexões a partir da experiência de um abrigo. 2013. Dissertação (Mestrado em Psicologia Social) - Instituto de Psicologia, Universidade de São Paulo, São Paulo, 2013.

LEWIS, L. Como ser uma criança na calçada pontuações etnográficas sobre algumas crianças em situação de rua na cidade do Recife. Revista Mediações, Londrina, v.9, n.2, 2004.

MALINOWSKI, B. "Introdução: Tema, método e objetivo desta pesquisa”. In: Argonautas do Pacífico Ocidental. (Coleção Os Pensadores) São Paulo: Abril Cultural, 1978.

NASCIMENTO, S. J. do. Múltiplas vitimizações: crianças indigenas kaiowá nos abrigos urbanos do Mato Grosso do Sul. Horizontes Antropológicos, n. 42, p. 265-292, 2014.
NAZARIO, R. Entre estar na casa e estar em casa: modos de ser criança em um contexto de acolhimento institucional. 37a Reunião Nacional da ANPEd, UFSC, Florianópolis. 2015. Disponível em <http://www.anped.org.br/sites/default/files/ trabalho-gt07-3900.pdf> Acesso em 17 nov. 2018.

OLIVEIRA, L. M. A. Vulnerabilidade Social e Situações de Risco. Ministério Público do Rio Grande do Norte, 2014.

OLIVEIRA, M. “Nhanhembo'é: infância, educação e religião entre os Guarani de M'Biguaçu, SC”, Revista Cadernos de Campo, nº 13, 2005.

PRADA, C. G; WEBER, L. N. D. 0 abrigo: análise de relatos de crianças vítimas de violência doméstica que vivem em instituições. Revista de Psicologia da Unesp, [S.1.], v. 5, n. 1, p. 12, mar. 2006.

SANTOS, A. M. A. dos. Acolhimento Institucional de crianças e adolescentes: mudanças na história brasileira. III Simpósio Mineiro de Assistentes Sociais. Belo Horizonte: 6 CRESS, 2013.

SARMENTO, M. J. Gerações e alteridade: interrogações a partir da sociologia da infância. Educação \& Sociedade. (Dossiê Temático Sociologia da Infância: Pesquisas com Crianças). CEDES - Brasil, Vol. 26, nº 91: 361-378, Maio/ago. 2005. Disponível em <http:// www.cedes.unicamp.br> Acesso em 10 nov. 2018.

SCHUCH, P. Família no plural: Considerações antropológicas sobre família e parentesco (à luz dos seus confrontos de significados num órgão da justiça juvenil). Apresentação oral, 2012. Disponivel em <http://www.pim.saude.rs.gov.br/a_PIM/ noticias/987/PatriceSchuch.pdf $>$ Acesso em 16 nov. 2019.

SOUSA, E. L. de. Infância no Caleidoscópio: descontruindo conceitos, desestabilizando teorias. Caderno Pós Ciências Sociais - São Luís, v. 2, n. 3, jan. /jun. 2005. P. 61

A infância das crianças

Tentehar-Guajajara no Maranhão. Fazendo Gênero 8 - Corpo, Violência e Poder. Florianópolis, de 25 a 28 de agosto de 2008. Disponivel em <http:// www.fazendogenero.ufsc.br/8/sts/ST24/ Emilene_Leite_Sousa_24.pdf> Acesso em 15 nov. 2018. 
Vivendo entre fendas:

Infância nas palafitas de São Luís do Maranhão. VII Reunião de Antropologia do Mercosul (RAM) - UFRGS, Porto Alegre, Brasil, 2007. Disponível em <http://www.emdialogo.uff.br/sites/default/ files/emilenesouzaVivendo_entre_Fendas.pdf> Acesso em 05 nov. 2018.

Autonomia Do Universo Infantil Versus Autonomia Infantil: A Agência Das Crianças No Contexto Camponês Capuxu. Temáticas - revista de pós-graduandos em ciências sociais da Unicamp, n. 51, p. 181-182, 2018. Disponivel em <https://www.ifch.unicamp.br/ojs/index.php/tematicas/article/download/3304/2443> Acesso em 15 fev. 2009

TASSINARI, A. Produzindo corpos ativos: a aprendizagem de crianças indígenas e agricultores através da participação nas atividades produtivas familiares. Horizontes Antropológicos, Porto Alegre, p. 141-172, 2015.

A participação de crianças indígenas e camponesas na produção de alimentos. Trabalho apresentado no $54^{\circ}$ Congresso Internacional de Americanistas no Simpósio: Children's Food Heritage. Anthropological Issues, Viena, 15 a 20 de julho, 2012.

Concepções Indígenas de Infância no Brasil. In Revista Tellus, ano 7, n.13, outubro, Campo Grande: UCDB, p.11-25, 2007.

Múltiplas Infâncias: o que a criança indígena pode ensinar para quem já foi à escola ou A Sociedade contra a Escola. Comunicação apresentada no $33^{\circ}$ Encontro da ANPOCS. Caxambu, 2009. 
RESUMO

Esta pesquisa dedica-se à análise da construção da autonomia infantil em crianças em situações de abrigo. As Casas Abrigo são espaços cuja organização repousa no excesso de regras e controle do tempo, do espaço e das ações infantis. Logo, esta pesquisa dedicou-se a investigar as estratégias através das quais as crianças - da Casa da Criança em Imperatriz, Maranhão - constroem sua individualidade junto ao grupo. Embora nestas instituições o controle excessivo não deixe espaço para a agência infantil, as crianças criam estratégias para garantir sua autonomia, burlando as regras estipuladas. Ora, em que situações as crianças fazem escolhas, se vivem sob constante observação dos cuidadores? De que forma imprimem suas impressões e sua individualidade? Este artigo mergulha no universo das crianças em situação de abrigo e revela seu modo de transformar um contexto de institucionalização em lar, marcando-o com sua agência. Este é um empreendimento etnográfico em construção.

\section{PALAVRAS-CHAVES}

Infância. Abrigo. Agência. Autonomia. Individualidade.

\section{ABSTRACT}

This research analyzes the construction of children's autonomy in shelter situations. Shelter Homes spaces are organized based on an excess of rules controlling children's time and space, as well as their actions. Therefore, this research focused on investigating the strategies used by children from Casa da Criança in Imperatriz, in Maranhão - to build their individuality in the group. In these institutions, even though the excess of control leaves no room for children's agency, children create strategies to guarantee their autonomy by circumventing the stipulated rules. Well, in what situations do children make choices if they live under constant observation of caregivers? How do they record their impressions and their individuality? This article delves into the world of sheltered children and reveals their way of transforming an institutionalization context into a home, marking it with their agency. This is an ethnographic action under construction.

\section{KEYWORDS}

Childhood. Shelter. Agency. Autonomy. Individuality. 
